\section{Is there a crisis in clinical consultations?}

\author{
John Launer
}

At medical school and beyond, a great deal of training focuses on the clinical consultation. There is a vast literature devoted to the subject. Thousands of medical educators worldwide spend their time inculcating good consulting skills in students and trainees. Yet we pay surprisingly little attention to the real-life conditions in which consultations actually take place. These are often far from ideal. Many patient encounters happen in circumstances where satisfactory conversations, let alone reflective and sensitive ones, are well nigh impossible.

The factors preventing good consultations are well known. Staff may be overworked and harassed, so that their priority is to do everything as quickly as possible. Colleagues may be hard pressed, so that everyone is reluctant seek to advice or call in help. Wards, out-patient rooms and casualty departments can be overcrowded and noisy, at time even chaotic. They may provide little or no opportunity for privacy or confidentiality. Paper and electronic records may be difficult to access - or they may be set out in ways that do not highlight important information. Fragmentation between specialties and departments, and poor systems of communication, may lead to long hold-ups in patient management. The presence of computers may enhance the consultation in some ways, but it is equally likely to introduce distractions, particularly through the requirement for continual data entry. The cumulative effect of these factors is that the consultation style that doctors learned in their training may be may be replaced by an automatic one that is aimed mainly at professional selfdefence and clinical fire-fighting.

It is worth asking how this state of affairs becomes accepted, or even normalised. The United Kingdom may not be unique in having these problems, but it may typify them. Here, clinicians often work within buildings and communication systems that were fit for purpose thirty or forty years ago, but have gradually become unsuitable for the levels of workload and complexity that now exist. Doctors who might have been surprised in the past if a test result had disappeared,

Correspondence to: Dr John Launer, Professional Development Department, Health Education England, Stewart House, 32 Russell Square, London WC1B 5DN, UK: john.launer@nwl.hee.nhs.uk or if they were unable find the past notes or contact a patient's GP for background information, may now accept these events as routine or inevitable. However, the effects of such failings in the system can include misdiagnosis, over-investigation, inappropriate treatment, unnecessarily prolonged admissions, avoidable harm, serious untoward incidents, and litigation, as well as clinician fatigue and burnout. ${ }^{1}$

\section{SOLVING THE PROBLEMS}

A recent round table discussion at the Kings Fund in London was an attempt to examine what may be a crisis in clinical consultations. ${ }^{2}$ It explored the idea that making it easier for clinicians simply to talk with patients may solve many problems that managers might assume need far more complex technological solutions. ${ }^{3}$ The discussion was introduced via a video link from Washington by Dr Don Berwick, one of the world's leading authorities on health care systems improvement. It was facilitated by Professor Chris Ham, chief executive of the King's Fund. They planned the meeting as a result of earlier encounters each of them had with Dr Gordon Caldwell, a physician in the south of England who has devoted much of his career to promoting effective processes of clinical care, through the use of more systematic ward rounds. ${ }^{4}$ At the round table, Caldwell himself presented a list of what he believes are the fundamental conditions for optimising clinical consultations (box 1).

These conditions are extremely simple. Yet, to the best of my knowledge, this is the first-ever clear formulation of what needs to be put in place before we can assume that all the sophisticated techniques of doctor-patient communication that we have learned can ever be put into practice. They include such basic things as allowing enough time for doctor and patient to prepare for their encounter, whatever the setting might be; making sure that all the relevant information is to hand; and encouraging a significant relative or friend of the patient to join the consultation if that is what the patient wishes. This is something that could be particularly important with frail elderly people, but is also an offer that almost any patient might welcome if given the choice. There are already places where practices such as
Box 1 How to optimise clinical consultations

- The patient should be as prepared as possible

- The clinician should be as prepared as possible

- The clinician should know the person before making the person into a patient

- The consultation should be unhurried for patient and clinician

- The clinician should be able to give undivided attention to the patient

- The clinician should be able to hear himself or herself think

- Ready supply of information into the consultation

- Confidentiality and dignity must be maintained

- The clinician should be regularly refreshed

- An important other person should be encouraged to participate in the consultation if the patient wishes

these are being adopted. ${ }^{5}$ Caldwell argues this should now be far more widespread.

As many of the participants at the Kings Fund discussion pointed out, this is all scarcely rocket science. If quality improvement initiatives could focus on the single issue of allowing clinicians to engage in proper dialogue with patients, this could act as a catalyst for far wider systems change: this includes the way teams function in hospitals, how laboratories interact with clinicians, how primary and secondary care relate to each other, and very much more. Putting medicine's core activity - the clinical consultation - back at the heart of everything the organisation does, could make a huge difference to cost efficiency and clinical outcomes.

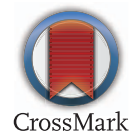

To cite Launer J. Postgrad Med J 2017;93:58.

Postgrad Med J 2017;93:58.

doi:10.1136/postgradmedj-2016-134691

\section{REFERENCES}

1 Caldwell G. What is the main cause of avoidable harm to patients? BMJ 2010;341:C4593.

2 Roundtable on the experiences of front line clinicians in NHS Hospitals Today. Kings Fund London, 18 Nov 2016.

3 Kaplan RS, Haas DA, Warsh J. Added value by talking more. N Engl J Med 2016;375:1918-20.

4 Launer J. What's wrong with ward rounds? PMJ 2013:89:733-4

5 Baathe F, Ahlborg Jr G, Lagström A, et al. Physician experience of patient-centered and team-based ward rounding - an-interview-based case study. Journal of Hospital Administration 2014;6:127-42. 